\title{
Counseling Case Report: Smoking Cigarette
}

\author{
Zewdu Girma* \\ Psychology Department, Madda Walabu University, Ethiopia \\ *Corresponding author: Zewdu Girma, Psychology Department, Madda Walabu University, Bale Robe, Ethiopia
}

\begin{abstract}
This paper is a counseling case report of 15 sessions on a client who has been diagnosed with smoking cigarette from Kelem Worq Preparatory School. CO6 was an 18 -year-old grade 12th social stream student in Keleme Worq Preparatory School. C06 was the second of the four children in his family. Assessment tools included a detailed interview and behavioral records. C06 has been smoking cigarette since grade eight. At the time of counseling CO6 smoked five per day. C06 drunk 4-6 glasses of beer occasionally, has done this for several years. Other than these drugs no other drug use reported. Many factors identified during the assessment were considered critical in accounting for the cause and persistence of CO6's cigarette smoking [1,2]. Cognitive behavioral counseling was the theoretical framework that informed the case formulation. The counselor used self-reports of the client as outcome measures. SQ3R study method, the five Ds and cognitive behavioral therapy technique were applied to solve the client's major problems of academic, smoking and alcohol drinking problems, respectively. Progress was evident by improved class attendance, more sustained focus on her academic studies, and continued improvement in sleep. The client has minimized his cigarette smoking and stopped his alcohol drinking.
\end{abstract}

\section{Introduction}

This paper is a counseling case report on a client who has been diagnosed with smoking cigarette from Kelem Worq Preparatory School. The assessment part has included the necessary identifying information with appropriate changes to shield the client's real identity [3]. As part of the treatment plan the presenting problems will be identified and matched to the criteria set forth in the Diagnostic and Statistical Manual of Mental Disorders, $4^{\text {th }}$ edition text revision (DSM-IV-TR) multi-axial diagnosis( its new version is also available, DSM-V).

\section{Nicotine or Tobacco Use Disorders}

Tobacco Use Disorder according to Diagnostic and Statistical Manual of Mental Disorders (DSM-IV-TR), diagnosis assigned to individuals who are dependent on the drug nicotine due to use of tobacco products. Tobacco contains the psychoactive drug nicotine, which is a central nervous system stimulant. The immediate effects of nicotine administration are tachycardia, hypertension, increased respiration, hyperglycemia, enhanced memory storage, improved concentration, and appetite suppression. Nicotine can be taken through several routes, including inhalation (smoking cigarettes, cigars, or pipes), chewing tobacco and snuff [4-8]. Nicotine produces dependence and withdrawal symptoms upon cessation of use, the onset of which occurs about one hour after the last dose. Withdrawal symptoms include irritability, annoyance, anxiety, and cravings for nicotine. Substance abuse disorders have high comorbidity with tobacco use disorder. People in early recovery from other drugs or alcohol tend to smoke heavily or chew tobacco.

Features of tobacco products that enhance their addictive potential include the rewarding properties of nicotine, the behavioral reinforcement of the hand- to -to mouth habit, lack of social support to cease smoking, the ease of access of tobacco products, and the cultural acceptance of tobacco products. Another factor which enhances nicotine's addictive qualities is bioengineering by tobacco companies, which add ammonia to nicotine to facilitate absorption and bioavailability (Figure 1). The Diagnostic and Statistical Manual of Mental Disorders indicates that risk factors for Tobacco Use Disorder include low-income levels, low level of Education, and diagnosis of the following disorders: conduct disorder, depressive disorder, anxiety disorders, personality disorders, psychotic disorders, and other substance use disorders. There is also a genetic component to Tobacco Use Disorder (American Psychiatric Association, 2013). 


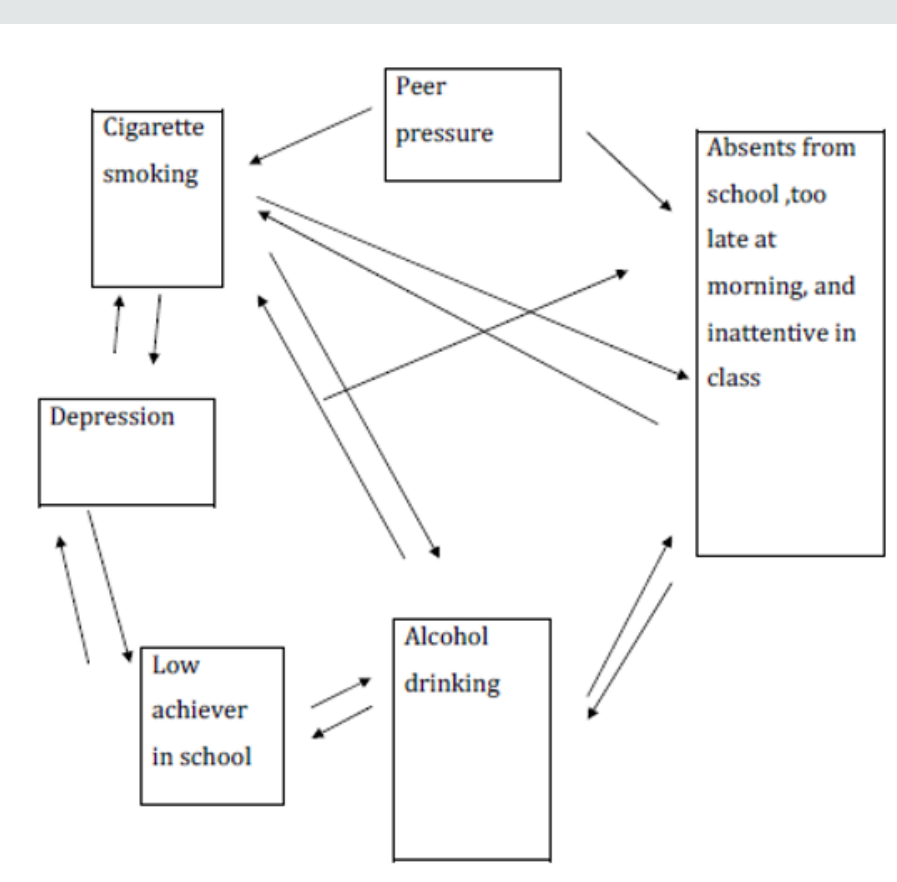

Figure 1: Showing the conceptualization frameworks for cigarette smoking.

\section{Case Description}

C06, code name of the client, was an 18-year-old grade $12^{\text {th }}$ social stream student in Keleme Worq Preparatory School. He was the second child among the four children. His father was 55 years old and lives outside Addis Ababa due to his workplace, but he visits his family in every weekend day. C06 had smooth communication with his father. His mother was housewife and learned up to grade 12. C06's mother was a smart for him, and she communicates friendly. His oldest sister in the family was 22 years old, and she was indulgent, reluctant to take great care of others. The rest younger sister and brother are 14 and 8 years old, respectively, and both of them have good communications with him. C06 described his parents' parenting style as democratic. C06's birth and childhood time were normal. He grew up in a close and loving family and recalls a happy childhood, and uneventful adolescence. As he reported that his parents were supportive and sensitive to his needs and encouraged his to be independent and responsible.

CO6 describes himself as a "good boy" who excelled socially and involved in many extracurricular activities. But he described himself as not good boy in academic performance as he was socially. He had a healthy self-esteem growing up and never engaged in risky behaviors or got into trouble other than smoking cigarette and drinking alcohol. C06's peer relationships during childhood and adolescence were good and he remains close with several high school friends and he was remembered by his jocks. C06 had also developed good peer relationships with neighborhood children and enjoyed with them sometimes. CO6 dated during elementary school and had a few casual relationships while he was high school students. Still he has not serious romantic relationship with anyone. C06 struggled to get out of bed in the morning, sometimes missing his morning classes. He stays up until 8:00 or 10:00 pm for eating and watching TV but he did not have much involvement during super time. And he had good self-esteem towards himself and had not suicidal ideation and never attempted suicide. Until this professional contact CO6 had not seen by any other professionals for a serious physical or mental problem.

\section{Clinical Assessment}

I would like to inform you that I have had 15 sessions in person with this client. The clinical assessment included a clinical interview and behavioral observation. CO6 has been smoking cigarette since grade eight. At the time of counseling the client smoked five per day. He started smoking again after awaking the first cigarette smoked was within the first 30 minutes. C06 drunk 4-6 glasses of beer occasionally, has done this for several years. He didn't see alcohol drinking as a problem. CO6 always smokes while drinking alcohol and C06 used coffee sometimes. Other than these drugs no other drug use reported. When CO6 became depressed he wants to smoke. In addition to his depression, head ace, watching his friends while they smoked or handed cigarette, drinking alcohols and sometimes his low performance in academic were the most triggering factors for his desire to smoke.

C06 had no past successes with behavior change: Quit smoking twice when he was grade nine for 2 months but relapsed. He, at the time of counseling, wanted to quit smoking to prevent the medical and social consequences of smoking. Even if $\mathrm{CO} 6$ was ready to quit 
at this time, CO6 was worried about his ability to succeed in his quitting. His limited time for self-care, peer pressures, his low selfconfidences to quitting, absences of social supports from his schools and families and his alcohol consumptions were his potential barriers to quitting. However, his strong motivation, strong health reasons, one previous quit attempt with some duration (2 months), his high self-esteem towards himself and, friends who want to quit with him were the assets of the client.

\section{Diagnostic Formulation}

Based on the assessment findings in the initial interviews, the following diagnosis was formulated.

Axis I: Substance abuse (cigarette smoking and alcohol drinking).

Axis II: No

Axis III: No

Axis IV: Problems related to the social environment (inadequate social support), and Educational Problems (academic problems and inadequate school environment)

Axis V: Moderate functioning

\section{Case Conceptualization}

Several factors identified during the assessment were considered critical in accounting for the etiology and persistence of C06's cigarette smoking. Cognitive behavioral model was the theoretical framework that informed the case formulation. The emphasis placed on developing a case formulation leads to treatment goal-setting and planning. CO6 was an eighteen-year-old boy who came from a medium class family. His chief complaint when he met the counselor was that he smoked cigarette accompanied by symptoms such as withdrawal and tolerance symptoms. C06 said that he can't concentrate in attending classes every day, which was why CO6 said he left school to smoke cigarette after break time. As the clinical interview revealed that the client had not exposed his smoking for his parents. C06's most serious problem was his cigarette smoking. From a behavioral perspective, these impulse control difficulties may have developed because of faulty learning experiences, including pressures from his close friends in school and neighboring, his modeling of his significant others' behavior and lack of guidance from parents. For C06's problem behaviors, precipitating factors included alcohol drinking, holding of cigarette by his friends and watching of theses friends while smoking, going to toilet with friends at break time and his thought of "I am poor in education". Client's perpetuating factors included his poor quit attempts, no support at school, withdrawal symptoms associated with cigarette smoking and his low self-confidence in succeeding in quitting cigarette smoking.
C06'S strengths include his sociable behaviors with school and neighboring friends. $\mathrm{CO} 6$ has a strong desire to quit smoking as CO6 believed that health and social consequences of cigarette smoking was inevitable. The counselor selected cognitive behavioral therapy for this client to solve his problems of cigarette smoking and its associated symptoms. It has been shown that cognitive-behavioral therapy, combined with a smoking cessation medication (such as the nicotine patch, nicotine gum, for example), is quite effective for smokers who are motivated to quit. Cognitive-behavioral counseling is an evidenced-based psychological treatment that focuses on identifying and changing maladaptive thoughts, emotions, and behaviors that trigger, worsen, and/or maintain a range of problems (such as depression, anxiety, addiction, etc.). Because changing your smoking-related behaviors-and restructuring your thoughts related to smoking urges- is essential to quitting, cognitivebehavioral counseling can effectively be applied to smoking cessation. An intensive cognitive-behavioral therapy program is typically composed of three phases: preparation, quitting, and maintenance (or relapse prevention).

\section{Treatment Plan and Course of Treatment}

Based on the case formulation, CO6 and the counselor collaborated in the development of the following prioritized list of problems and treatment goals. The order and relative importance placed on these goals was largely determined by the client, although there was input from the counselor in directing treatment efforts to goals that would have the most impact on CO6's cigarette smoking and its associated symptoms, and had the greatest likelihood of success. The treatment plan followed the problem format, a format that presents the target problems with its major goal and objectives and intervention methods in structured form.

Problem-1: low academic performance

a) As evidenced by: low results grade to grade.

b) As evidenced by: poor class attendance.

c) As evidenced by: lack of study skills.

d) As evidenced by: absent from schools.

e) As evidenced by: late in the morning to go to school.

Goal-1: to improve academic performance

Objectives and Interventions.

Objective-1: teaching study skills

Interventions: The SQ3R study method was employed to target co6's poor study skills and to improve his academic performance.

Objective -2: Increase class attendances

Interventions: To improve class attendance, a behavioral contingency was developed to ensure C06's woke up by 7:00 am 
so he could attend all his scheduled classes for that day. In addition, C06 would shower, eat a light breakfast, and walk to school. If he completed this schedule 3/5 days, C06 would reward himself by going pool houses for the weekend or to the movies with classmate.

\section{Objective -3: work on sleep difficulty}

Intervention: Poor class attendance and an inability to study were major contributors to poor academic performance. It was decided to target C06's sleep difficulties that were a major cause of missing classes and daily fatigue that made it difficult to study. Maladaptive sleep-related behaviors were identified, and corrective homework assigned. The client and the counselor set up a sleep log and agreed to keep the sleep log, maintain regular sleep hours, eliminate daytime naps, to make sure the bedroom has oxygen, and restrict bedroom activities to sleep.

\section{Problem 2: Cigarette Smoking}

a) As evidenced by: smoked for five years.

b) As evidenced by: nicotine dependence withdrawal.

c) As evidenced by: fugue out of school for smoking.

d) As evidenced by: slum physical appearances.

Goal-2: Cigarette Smoking Cessation

Objectives and Interventions.

Objective 1: To confront with the urge to smoke

\section{Intervention}

To achieve this objective the client and counselor applied the five Ds
a) Delay, even for a short while.
b) Drink water.
c) Deep breathing.
d) Do something different and,
e) Discuss the craving with another person.

Objective 2: Teaching different behavioral tips to quit smoking cigarette

\section{Intervention tips}

a) Write outa list of reasons to quit and display it prominently e.g. on wall.

b) Get rid of all tobacco products, ashtrays, lighters, matches, etc. from all areas which you inhabit.

c) Clean all clothes in order to remove cigarette smell.

d) Enlist the support of non-smoking friends, relatives, and workmates. e) Change the environmental cues, e.g. the telephone often causes a reflex action to smoke, move the telephone to another place to change the cue.

f) Keep hands busy e.g. knitting, gardening, drawing, origami.

g) Sit in non-smoking areas.

h) Positive self-talk.

i) Try to avoid stressful situations in the immediate period after stopping.

j) Set aside the money normally spent on cigarettes to buy something as a reward do not drink alcoholic beverages because these are associated with relapse.

k) Avoid, even temporarily, social situations normally associated with smoking. practice saying, "No thank you, I don't smoke.

l) Ask other smokers not to give cigarettes, offer to buy cigarettes or smoke in the patient's presence.

m) Think positive and remember your reasons for quitting in the first place.

n) View quitting as a day-at-a-time process rather than an immediate lifelong commitment.

Problem 3: alcohol drinking

Goal 3: To stop drinking alcohol: The psychologist also offered cognitive behavioral therapy techniques for his alcohol abuse and some behavioral tips.

\section{Progresses}

The counselor used self-reports as outcome measures. The therapist reviewed co6's sleep log and daily activity record to evaluate the success of these interventions at modifying sleep behavior and class attendance. Progress was evident by improved class attendance and a more consistent bedtime routine. C06 reported better class attendance; more sustained focus on her academic studies, and continued improvement in sleep. The client has minimized his cigarette smoking and stopped his alcohol drinking. The treatment is still under supervision.

\section{Strengths and Weakness}

Use of the core conditions of (empathy, genuine and unconditional positive regard) as relationship building throughout the whole counseling processes helped me to express my values, reactions, and feelings as they became appropriate to what was happening in the therapy sessions. It helped me to create a trusting working relationship with my client. The process helped the counselor to understand the value of supervision. The supervision helped the counselor to identify themes that had not been obvious to 
the counselor. It helped the counselor articulate the counselor role as a counselor. Supervision helped the counselor to identify areas where the counselor was not challenging my client enough and to be conscious of any manipulative signs by client and how to handle them. Supervision also helped the counselor to identify strengths in empathizing, listening, summarizing, and paraphrasing. Sometimes client would tend to talk very little and at such times the counselor would tend talk more and to give advice to my client may consider as weakness.

\section{Consent for Publication}

This part is not applicable because the manuscript contains no individual person's data in any form (including individual details, images, or videos.

\section{Competing Interests}

The author declares that he has no competing interests.

\section{References}

1. (2013) American Psychiatric Association. Diagnostic and Statistical Manual of Mental Disorders. $5^{\text {th }}$ (edn.), Arlingon, American Psychiatric Association, USA.

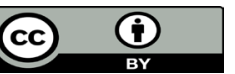

This work is licensed under Creative Commons Attribution 4.0 License

To Submit Your Article Click Here:

Submit Article
2. (2008) Centers for Disease Control and Prevention: Cigarette smoking among adults and trends in smoking cessation. Morbidity and Mortality Weekly Report. 58:1227-1232.

3. (2008) Centers for Disease Control and Prevention: Smoking-attributable mortality, years of potential life lost, and productivity losses. Morbidity and Mortality Weekly Report 57(45): 1226-1228.

4. Corey G (2009a) Case Approach to Counselling and Psychotherapy. $7^{\text {th }}$ (edn.), Thomson.

5. Corey G (2009b) Theory and Practice of Counselling and Psychotherapy. $8^{\text {th }}$ (edn.), Belmont.

6. Culley J (1996) Integrative Counselling Skills in Action. $6^{\text {th }}$ (edn.), Sage Publications Ltd.

7. Parsons AC, Shraim M, Inglis J, Aveyard P, Hajek P (2009) Interventions for preventing weight gain after smoking cessation. Cochrane Database Syst Rev 1:CD006219.

8. Vinci C, Copeland AL, Carrigan MH (2012) Exposure to negative affect cues and urge to smoke. Exp Clin Psychopharmacol 20(1): 47-55.

\begin{tabular}{|l|l|}
\hline SJPBS & $\begin{array}{c}\text { Scholarly Journal of Psychology } \\
\text { and Behavioral Sciences }\end{array}$ \\
Assets of Publishing with us
\end{tabular}

